\title{
Implementasi Multilayer Perceptron Pada Jaringan Saraf Tiruan Untuk Memprediksi Nilai Valuta Asing
}

\author{
Tommy Ferdian Hadimarta ${ }^{1}$, Rani Rotul Muhima ${ }^{2}$, Muchammad Kurniawan ${ }^{3}$ \\ 1,2,3 Jurusan Teknik Informatika, Fakultas Teknik Elektro dan Teknologi Informasi \\ Email: ${ }^{1}$ trickytommy@,hotmail.com
}

\begin{abstract}
In the context of FOREX investment, the fluctuation of currency becomes a common thing in which movement is greatly influenced by supply and demand. If the demand is higher, the price will increase and conversely, if the supply is higher, the price will go downward. There is a principle that the behavior of price patterns will repeat randomly and make unpredictable movement of FOREX. These patterns of currency fluctuation have deceived many investors and brought losses and even capital failure. Basically, the value of foreign exchange belongs to the data of time series and Multilayer Perceptron is very suitable to process data of time series as it is often used to make prediction. Therefore, this research aimed at implementing Multilayer Perceptron in the artificial nerve network for predicting the value of foreign exchange on the available resources using the attributes of open, high, low, and close. To process the data from the existing attributes, there must be initialization first in X1 (open), X2 (high), and X3 (low) as the inputs and $Y$ (close) as the data target, and then they were normalized so as to calculate sigmoid. The increasing number of epoch does not guarantee that the errors will be smaller. On the contrary, perhaps, the error value will increase. The best result of training occurred by epoch 200 and learning rate 3 within the smallest values of MSE 281.02518, MAD 13.168, and deviation standard 10.294.
\end{abstract}

Keywords: Multilayer Perceptron, Forex Value, Currencies, MSE, MAD, Deviation Standard

Abstrak. Dalam dunia investasi FOREX, fluktuasi mata uang menjadi hal yang biasa. Pergerakan tersebut dipengaruhi oleh banyaknya permintaan dan penawaran, jika permintaan lebih tinggi maka harga cenderung akan naik, dan jika penawaran lebih tinggi maka harga akan cenderung turun. Terdapat prinsip bahwa perilaku pola harga akan terulang kembali, pola-pola tersebut berulang secara acak, dan menjadikan forex ini terlihat susah untuk diprediksi pergerakannya. Tidak sedikit investor yang tertipu oleh pola fluktuasi mata uang, sehingga berakhir dengan kerugian dan bahkan sampai kehabisan modal. Multilayer Perceptron sangat cocok digunakan dalam mengolah data time series dan sering digunakan dalam memprediksi. Nilai valuta asing termasuk data time series sehingga pada skripsi ini dirancang sebagai Implementasi Multilayer Perceptron pada Jaringan Saraf Tiruan untuk memprediksi nilai valuta asing. Langkah langkah awal yang dilakukan dalam skripsi ini dengan mengambil data nilai valuta asing pada sumber sumber yang tersedia dengan mempunya atribut open, high, low, close. Untuk mengolah data dari atribut yang tersedia di beri inisialisasi terlebih dahulu dengan X1 (open), X2 (high), X3 (low) sebagai inputan dan Y (close) sebagai target data tersebut di normalisasi untuk menghitung sigmoid. Jumlah epoch semakin banyak belum menentukan bahwa error semakin kecil, bahkan akan bisa menaikkan nilai error tersebut. Hasil pelatihan terbaik adalah dengan epoch 200 dan learning rate 3 dengan nilai MSE 281.02518, MAD 13.168, standar deviasi 10.294 terkecil.

Kata Kunci: Multilayer Perceptron, Forex, Nilai Valuta Asing, Curencies, MSE, MAD, Standar Deviasi.

\section{Pendahuluan}

Menjaga kerahasiaan informasi merupakan hal yang sangat penting. Untuk menjalankan aktivitas bisnis baik export dan import setiap negara memerlukan konversi uang ke negara lain sehingga adanya Valas (valuta asing) juga sering disebut FOREX (Foreign Exchange). Bisnis ini 
terjadi karena adanya perbedaan nilai mata uang antar negara. Negara tersebut diantaranya Amerika (USD), Eropa (EUR), Inggris (GBP), Jepang (JPY), Australia (AUD), New Zealand (NZD), Swiss (CHF) dan Canada (CAD). Dari mata uang tersebut merupakan peran penting dalam ekonomi dunia yang disebut currencies. Terdapat prinsip bahwa perilaku pola harga akan terulang kembali, pola-pola tersebut berulang secara acak, dan menjadikan forex ini terlihat susah untuk diprediksi pergerakannya. Tidak sedikit investor yang tertipu oleh pola fluktuasi mata uang, sehingga berakhir dengan kerugian dan bahkan sampai kehabisan modal. Tercatat di perusahaan Tickmill Ltd bahwa transaksi yang terjadi setiap hari senilai dua miliar dollar dari seluruh dunia, dan dapat terjadi kerugian dan keuntungan dari nilai tersebut. Kerugian atau keuntungan yang didapatkan bisa sangat besar. Seorang investor haruslah mempunyai sebuah informasi tentang pola naik dan turunnya mata uang yang dapat dijadikan referensi untuk melakukan transaksi, agar dapat meminimalkan kerugian dan memaksimalkan keuntungan.

Multilayer Perceptron sangat cocok digunakan dalam mengolah data time series dan sering digunakan dalam memprediksi. Nilai valuta asing termasuk data time series sehingga pada skripsi ini dirancang sebagai Implementasi Multilayer Perceptron pada Jaringan Saraf Tiruan untuk memprediksi nilai valuta asing.

\section{Tinjauan Pustaka}

\subsection{Valuta Asing}

Valuta asing atau foreign exchange merupakan bisnis pertukaran mata uang asing yang memanfaatkan perbedaan nilai mata uang antar negara di seluruh dunia, valuta asing ini juga difungsikan sebagai alat pembayaran untuk membiayai transaksi ekonomi keuangan internasional (Wijatmoko, 2009).

\subsection{Data Time Series}

Data deret waktu (time series) adalah nilai-nilai suatu variabel yang secara berurutan menurut waktu. Time series dapat berkelanjutan atau diskrit, dalam time series pengamatan diukur pada setiap kejadian waktu dimana time series berisi pengamatan yang diukur pada titik waktu berkelanjutan. Misalnya pembacaan suhu, aliran sungai, konsentrasi proses kimia dan lain-lain, di sisi lain populasi kota tertentu, produksi sebuah perusahaan, nilai tukar antara dua mata uang yang berbeda dapat mewakili time series yang berbeda. Biasanya dalam time series, pengamatan berurutan dicatat pada interval waktu yang sama, seperti pemisahan jam, harian, mingguan, bulanan atau tahunan. (Adhikari D. R., 2013).

\subsection{Jaringan Saraf Tiruan}

Jaringan saraf tiruan bisa dibayangkan seperti otak buatan di dalam cerita-cerita fiksi ilmiah. Otak buatan ini dapat berpikir seperti manusia, dan juga sepandai manusia dalam menyimpulkan sesuatu dari potongan-potongan informasi yang diterimanya. Khayalan manusia tersebut mendorong para peneliti untuk mewujudkannya. Komputer diusahakan agar bisa berpikir sama seperti cara berpikir manusia. Caranya adalah dengan melakukan peniruan terhadap aktivitas-aktivitas yang terjadi di dalam sebuah jaringan saraf biologis (Aji , 2016).

Pembagian arsitektur jaringan saraf tiruan bisa dilihat dari kerangka kerja dan skema interkoneksi. Kerangka kerja jaringan saraf tiruan bisa dilihat dari jumlah lapisan (layer) dan jumlah node pada setiap lapisan. Lapisan-lapisan penyusun jaringan saraf tiruan dapat dibagi menjadi tiga, yaitu lapisan input, lapisan tersembunyi, lapisan output:

1. Lapisan input Node-node di dalam lapisan input disebut unit-unit input. Unit-unit input menerima input dari dunia luar. Input yang dimasukkan merupakan penggambaran suatu masalah.

2. Lapisan tersembunyi Node-node di dalam lapisan tersembunyi disebut unit-unit tersembunyi. Output dari lapisan ini tidak secara langsung dapat diamati.

3. Lapisan output Node-node pada lapisan output disebut unit-unit output. Keluaran atau output dari lapisan ini merupakan output jaringan syaraf tiruan terhadap suatu permasalahan. 
Gambar 2 merupakan salah satu contoh arsitektur jaringan saraf tiruan multilayer yang terdiri dari sebuah lapisan input, sebuah lapisan tersembunyi, dan sebuah lapisan output. $\mathrm{W}_{\mathrm{ij}}$ adalah bobot antara lapisan input dengan lapisan tersembunyi, $\mathrm{W}_{\mathrm{jk}}$ adalah bobot antara lapisan tersembunyi dengan lapisan output. Sebuah neuron (disebut juga node atau unit) yang terletak di dalam lapisan input akan memiliki fungsi aktivasi dan pola koneksi bobot yang dengan neuron-neuron lainnya yang terletak di dalam lapisan input. Demikian pula halnya sebuah neuron yang terletak di dalam lapisan tersembunyi akan memiliki aktivasi dan pola koneksi bobot yang sama dengan neuron-neuron lainnya yang terletak di dalam lapisan tersembunyi (Dr.Hendra, et al., 2018).

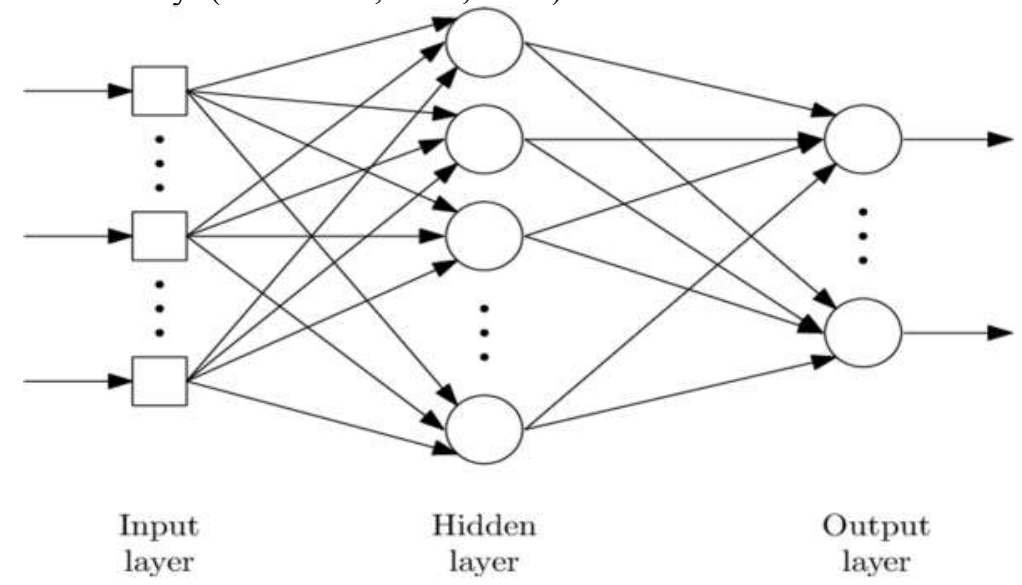

Gambar 1. Arsitektur Jaringan Saraf Tiruan

\subsection{Multilayer Perceptron}

Multilayer Perceptron (MLP) merupakan ANN dari Perceptron. Berupa ANN feedforward dengan satu atau lebih hidden layer. Biasanya, jaringan terdiri dari satu layer neuron komputasi keluaran. Sinyal masukan di propagasikan dengan arah maju pada layer per layer. Contoh arsitektur MLP diberikan pada Gambar 2.1. Setiap layer dalam MLP memiliki fungsi khusus. Layer masukan berfungsi menerima sinyal/vektor masukan dari luar mendistribusikannya ke semua neuron dalam hidden layer. Layer keluaran menerima sinyal keluaran (atau dengan kata lain stimulus pola) dari hidden layer dan memunculkannya sinyal/nilai/kelas keluaran dari keseluruhan jaringan.

Banyak algoritma pelatihan yang tersedia, tetapi yang paling populer adalah Backpropagation. Cara pelatihan yang dilakukan algoritma Backpropagation sama dengan Perceptron. Sejumlah data latih sebagai data masukan diberikan pada jaringan. Jaringan menghitung pada keluaran, jika ada error (perbedaan antara target keluaran yang di inginkan dengan nilai keluaran yang didapatkan) maka bobot dalam jaringan akan diperbaharui untuk mengurangi error tersebut.

Persamaan yang digunakan untuk pelatihan MLP Backpropagation 2.1 :

$v=\sum_{i=1}^{r} x_{i} \cdot w_{i}$

$v=$ Nilai keluaran hidden layer.

$x_{i}=$ Nilai input/fitur.

$w_{i}=$ Nilai bobot.

Nilai $r$ adalah jumlah masukan (fitur) data masukan, $\mathrm{x}$ merupakan nilai fitur/vektor, $\mathrm{w}$ adalah bobot vektor. Nilai $\mathrm{v}$ tersebut kemudian di aktivasi untuk menghasilkan sinyal keluaran. Fungsi aktivasi yang digunakan adalah sigmoid biner atau sigmoid bipolar. Fungsi aktivasi sigmoid menjadi persamaan 2.2 :

$y=\frac{1}{1+e^{-v}}$

$y=$ Nilai sigmoid.

$\mathrm{e}=$ Eksponen .

Untuk merambatkan sinyal error, dimulai dari layer keluaran dan berjalan kembali ke hidden layer. Sinyal error di neuron $\mathrm{k}$ pada iterasi $\mathrm{p}$ diberikan pada persamaan 2.3 : 
$e_{k}(P)=y_{d k}(P)-y_{k}(P)$

$\mathrm{e}_{\mathrm{k}} \quad=$ Nilai selisih / error.

$\mathrm{y}_{\mathrm{dk}} \quad=$ Nilai Sebenarnya.

$\mathrm{y}_{\mathrm{k}} \quad=$ Nilai prediksi.

Prosedur yang digunakan untuk memperbaharui bobot pada koneksi hidden layer ke output layer 2.4 :

$w_{j k}(p+1)=w_{j k}(p)+\Delta w_{j k} \quad$ (2.4) $\Delta w_{j k}=$ Koreksi

bobot.

$\mathrm{w}_{\mathrm{jk}} \quad=$ Nilai bobot

Kondisi yang dialami adalah masukan neuron pada output layer berbeda dari input neuron pada input layer $\mathrm{x}_{\mathrm{i}}$. Oleh karena itu yang digunakan untuk menghitung koreksi bobot adalah sinyal output neuron $\mathrm{j}$ pada hidden layer $\mathrm{y}_{\mathrm{j}}$ untuk menggantikan $\mathrm{x}_{\mathrm{i}}$, Koreksi bobot dalam MLP dihitung dengan persamaan 2.5:

$$
\begin{array}{ll}
\Delta w_{j k}(p) & =\eta * x_{i}(p) * \delta_{j}(p) \\
\eta & =\text { Learning rate. } \\
\delta_{j}(p) & =\text { Gradien error. } \\
\mathrm{p} & =\text { Iterasi } \\
\Delta w_{j k} & =\text { Koreksi bobot. }
\end{array}
$$

$\eta$ adalah laju pembelajaran, sedangkan $\delta_{j}(p)$ adalah gradien error pada neuron k dalam output layer pada iterasi ke $\mathrm{p}$.

Untuk menghitung gradien error pada fungsi aktivasi sigmoid biner didapatkan 2.6:

$\delta(p)=y_{k}(p) *\left(1-y_{k}(p)\right) * e_{k}(p) * w_{j k}$

\subsection{MSE}

Mean Squared Error (MSE) adalah metode lain untuk mengevaluasi metode peramalan. Masingmasing kesalahan atau sisa dikuadratkan. Pendekatan ini mengatur kesalahan peramalan yang besar karena kesalahan-kesalahan itu dikuadratkan. Metode itu menghasilkan kesalahan-kesalahan sedang yang kemungkinan lebih baik untuk kesalahan kecil, tetapi kadang menghasilkan perbedaan yang besar. MSE merupakan cara kedua untuk mengukur kesalahan peramalan keseluruhan. MSE merupakan rata-rata selisih kuadrat antara nilai yang diramalkan dan yang diamati. Kekurangan penggunaan $M S E$ adalah bahwa MSE cenderung menonjolkan deviasi yang besar karena adanya pengkuadratan (S, et al., 2015). Persamaan untuk menghitung MSE terdapat pada persamaan 2.7 .

$M S E=\sum{ }_{t=1}^{n} \frac{\left(X_{t}+F_{t}\right)^{2}}{n}$

$\mathrm{F}=$ nilai peramalan pada periode $\mathrm{t}$

$\mathrm{n}=$ jumlah data

$\mathrm{x}_{\mathrm{t}}=$ data aktual

\section{Metode Penelitian}

Langkah langkah awal yang dilakukan dalam skripsi ini dengan mengambil data nilai valuta asing pada sumber sumber yang tersedia dengan mempunya atribut open, high, low, close. Untuk mengolah data dari atribut yang tersedia di beri inisialisasi terlebih dahulu dengan X1 (open), X2 (high), X3 (low) sebagai inputan dan Y (close) sebagai target. Langkah awal yang dilakukan mengambil data nilai valuta asing kemudian nilai valuta asing tersebut di normalisasikan, nilai valuta asing di normalisasikan agar dapat digunakan untuk menghitung fungsi aktivasi pada JST , fungsi aktifasi tersebut adalah sigmoid, untuk menghitung sigmoid menggunakan nilai diantara $0-1$ maka perlunya normalisasi.

Selanjutnya di dalam JST terdapat pelatihan data training dan data testing. Data digunakan pada data pelatihan training dan juga pada data testing, dari training tersebut menghasilkan model, model tersebut digunakan sebagai inputan pada tahap testing, setelah tahap training dan testing selesai hasil dari keduanya diukur menggunakan MSE.

Pada metode jaringan saraf tiruan, akan dilakukan pelatihan Feedforward selanjutnya pada pelatihan Backward, maka akan dihitung error, jika error tidak sesuai dengan ketentuan maka akan di 
ulangi kembali sehingga error memenuhi ketentuan dan akan menghasilkan model yang di inginkan. Flowchart sistem bisa dilihat pada Gambar 3.

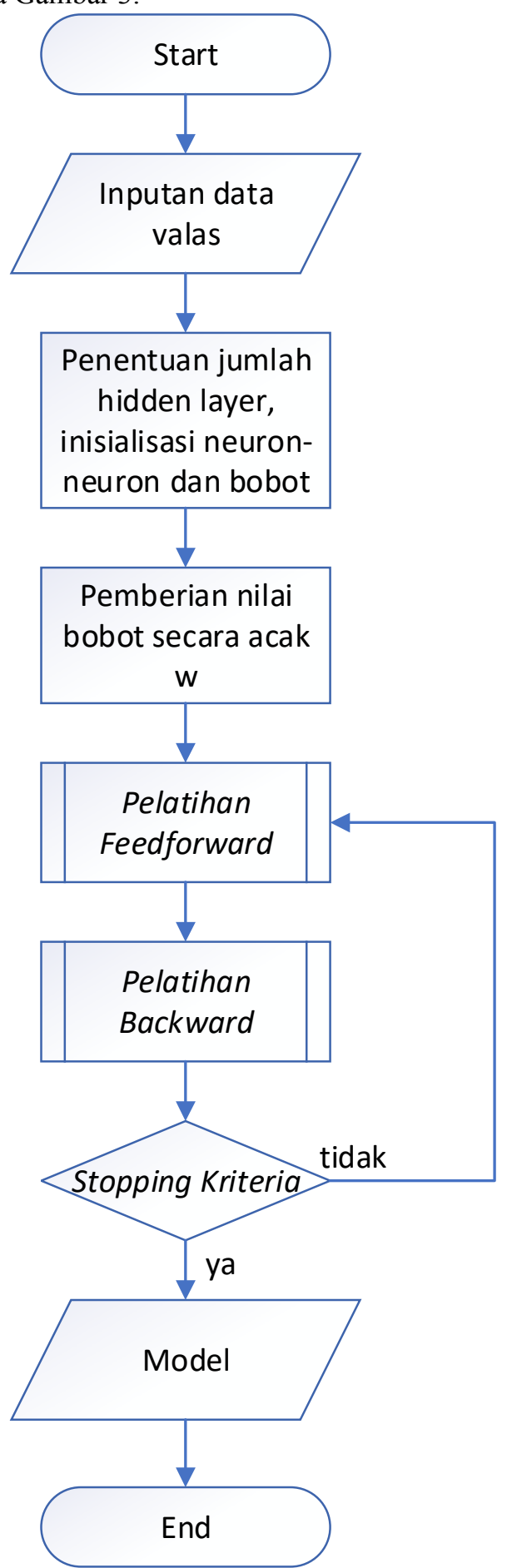

Gambar 2. Flowchart Jaringan Saraf Tiruan Multilayer Perceptron 


\section{Hasil Dan Pembahasan}

Tabel 1. Sekenario Uji Coba

\begin{tabular}{|c|c|c|c|c|}
\hline Urutan & Data Training & Data Testing & Epoch & Rearning \\
\hline Uengujian & & & Rate \\
\hline Urutan & Data Training & Data Testing & Epoch & Rate \\
\hline Uji coba 1 & $2017-2018$ & 2019 & 300 & 0.1 \\
\hline Uji coba 2 & $2017-2018$ & 2019 & 300 & 0.05 \\
\hline Uji coba 3 & $2017-2018$ & 2019 & 300 & 0.01 \\
\hline Uji coba 4 & $2017-2018$ & 2019 & 1000 & 0.1 \\
\hline Uji coba 5 & $2017-2018$ & 2019 & 1000 & 0.05 \\
\hline Uji coba 6 & $2017-2018$ & 2019 & 1000 & 0.01 \\
\hline Uji coba 7 & tahun 2019 & bulan tahun 2019 & 2000 & $1,2,3$ \\
\hline & & & & \\
\hline
\end{tabular}

Pada Tabel 1. dapat dilihat sekenario uji coba yang akan telah dilakukan.

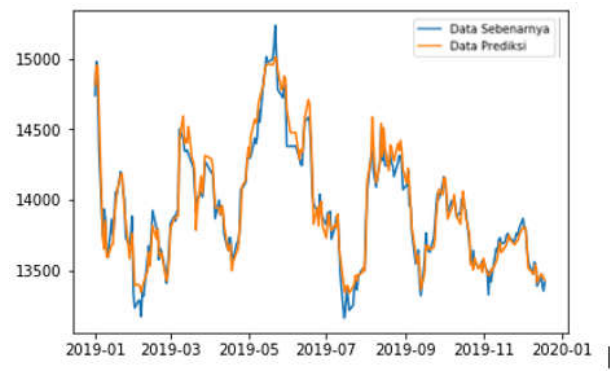

\section{Gambar 3. Hasil Prediksi Salah Satu Uji Coba}

Pada Tabel 2. merupakan rekapan hasil pengukuran dari uji coba 1 sampai uji coba ke 6 .

Tabel 2. Hasil Pengukuran

\begin{tabular}{|c|c|c|c|c|c|c|c|}
\hline \multirow{2}{*}{ Epoch } & \multicolumn{3}{|c|}{ Keterangan } & \multirow{2}{*}{$\begin{array}{c}\text { MSE } \\
\text { Testing }\end{array}$} & \multirow{2}{*}{ MAD } & \multirow{2}{*}{$\begin{array}{l}\text { Standar } \\
\text { Deviasi }\end{array}$} & \multirow{2}{*}{ Epoch } \\
\hline & Rate & Data Training & $\begin{array}{c}\text { Data } \\
\text { Testing }\end{array}$ & & & & \\
\hline 100 & 3 & 20 hari tiap bulan pada th 2019 & $\begin{array}{l}\text { sisa hari } \\
\text { tiap bulan }\end{array}$ & 0.03354 & 635.112 & 20.338 & 14.974 \\
\hline 150 & 3 & 20 hari tiap bulan pada th 2019 & $\begin{array}{l}\text { sisa hari } \\
\text { tiap bulan }\end{array}$ & 0.02853 & 316.987 & 13.262 & 11.952 \\
\hline 200 & 3 & 20 hari tiap bulan pada th 2019 & $\begin{array}{l}\text { sisa hari } \\
\text { tiap bulan }\end{array}$ & 0.02709 & 281.025 & 13.280 & 10.294 \\
\hline
\end{tabular}




\begin{tabular}{|c|c|c|c|c|c|c|c|}
\hline ..... & $\cdots \cdots$ & $\cdots \cdots$ & $\cdots \cdots$ & $\cdots \cdot$ & $\cdots \cdots$ & $\cdots \cdots$ & $\cdots \cdots$ \\
\hline 1900 & 3 & 20 hari tiap bulan pada th 2019 & $\begin{array}{l}\text { sisa hari } \\
\text { tiap bulan }\end{array}$ & 0.02290 & 472.223 & 17.560 & 12.881 \\
\hline 1950 & 3 & 20 hari tiap bulan pada th 2019 & $\begin{array}{l}\text { sisa hari } \\
\text { tiap bulan }\end{array}$ & 0.02289 & 490.485 & 17.968 & 13.027 \\
\hline 2000 & 3 & 20 hari tiap bulan pada th 2019 & $\begin{array}{l}\text { sisa hari } \\
\text { tiap bulan }\end{array}$ & 0.02144 & 492.604 & 18.416 & 12.463 \\
\hline & MSE & & & 0.02131 & 281.02518 & 13.16780 & 10.29364 \\
\hline
\end{tabular}

Dari Tabel 2. dapat dilihat merupakan salah satu hasil pengukuran yang telah dilakukan dengan menggunakan metode Multilayer Perceptron

Tabel 3. Contoh Hasil Prediksi

\begin{tabular}{|c|c|c|c|}
\hline & Abasolute error & Data Prediksi & Data Sebenarnya \\
\hline $\mathbf{0}$ & 7.853995 & 14149.253314 & 14157.107309 \\
\hline $\mathbf{1}$ & 39.713213 & 14129.511036 & 14089.797823 \\
\hline $\mathbf{2}$ & 16.930418 & 14060.246876 & 14077.177294 \\
\hline $\mathbf{3}$ & 7.821189 & 14090.390319 & 14098.211509 \\
\hline $\mathbf{4}$ & 11.802134 & 14115.857275 & 14127.659409 \\
\hline $\mathbf{5}$ & 75.819977 & 14070.543150 & 13994.723173 \\
\hline $\mathbf{. 6}$ & $\mathbf{n}$ & & $\ldots$ \\
\hline $\mathbf{7 6}$ & 14.209953 & 13976.306376 & 13990.516330 \\
\hline $\mathbf{7 7}$ & 14.209953 & 13976.306376 & 13990.516330 \\
\hline $\mathbf{7 8}$ & 1.083081 & 13979.336825 & 13980.419907 \\
\hline $\mathbf{7 9}$ & 7.277327 & 13968.935736 & 13976.213064 \\
\hline $\mathbf{8 0}$ & 3.189860 & 13957.527340 & 13954.337481 \\
\hline $\mathbf{8 1}$ & 23.957693 & 13942.957693 & 13919.00000 \\
\hline & MSE & 297.650169 & \\
\hline & MAD & 13.196062 & \\
\hline & Standar Deviasi & 12.76269 & \\
\hline & & & \\
\hline & & & \\
\hline & & & \\
\hline
\end{tabular}


Pada Gambar 7 dapat dilihat bahwa nilai MSE 297.650169, MAD 13.196062, Standar Deviasi 12.76269

\section{Kesimpulan}

Berdasarkan pengian yang telah beberapa kali dilakukan terhadap data nilai valuta asing dengan menggunakan metode Multilayer Perceptron, maka dapat ditarik kesimpulan sebagai berikut:

1. Jumlah epoch semakin banyak belum menentukan bahwa error semakin kecil, bahkan akan bisa menaikkan nilai error tersebut. Hasil pelatihan terbaik adalah dengan epoch 200 dan learning rate 3 dengan nilai MSE 281.02518, MAD 13.168, standar deviasi 10.294 terkecil.

2. Pada learning rate yang sama dengan epoch yang bervariasi pola yang dihasilkan hampir sama dalam menurunkan error.

\section{Referensi}

Adhikari Dr. Ratnadip An Introductory Study on Time Series Modeling and Forecasting [Jurnal]. 2013. - hal. 182

Aji Sudarsono JARINGAN SYARAF TIRUAN UNTUK MEMPREDIKSI LAJU PERTUMBUHAN PENDUDUK MENGGUNAKAN METODE BACPROPAGATION [Jurnal]// Media Infotama. - 2016. - hal. 61-69.

Dr.Hendra Jaya,M.T [et al.] KECERDASAN BUATAN [Buku]. - Makasar: Fakultas MIPA Universitas Negeri Makassar, 2018. 